$\$ 250,000$. That is a phase of industrial work that has probably never occurred to many in this room. Now it is not well perhaps for us to get.down to the sordid or financial side of this question, but in discussing these questions in all their bearings it is just as well to keep in mind what Dr. Hugh Cabot said about the "human side of the thing." The bringing back to work as quickly as possible of sick or injured persons and the saving of the overhead expenses is the real reason for industrial work in factories today.

In another part of this paper, Dr. Stanton brought up a new idea, and that is whether you should have an open or a closed hospital. Heretofore I had been in favor of a closed hospital, especially in small communities. After hearing this paper, I don't know that I am so strongly in favor of a closed hospital. There surely is something to be said in favor of the open hospital. The law recognizes fundamentally the open hospital, when it says that the person who is injured under compensation law may choose his own physician. To my mind, that recognizes fundamentally an open hospital. Now I don't know, and I cannot say how an open hospital could exist in a large community like Baston, or in some of the larger cities in Massachusetts, but I do think that in a small community the open hospital plan could be worked out to great advantage, and then, if successful, the plan could be taken to the larger cities. The objection to the open hospital has frequently been that there might be five or six physicians coming in in the morning to make their visits,that they might all come at one time, and the number of nurses would not be sufficient to attend each physician, or that one physician might come at nine o'clock and three or four at intervals during the morning and there would be no regular time for physicians' visits, and this condition would incur great expense and, some maintain, would not be workable. I think that could all be changed. I think the institution of the open hospital in the small community is something which would be appreciated and is something along constructive lines which has not been done before. As I said in opening, we must remember that we are no longer practicing medicine purely. We are concerned with the affairs of the state. We have come to a new era and we are going on in a new way, and it is up to the men here to give to the com-munity something constructive.

I would like to tell you more of my experiences before legislative committees and commissions when from time to time I and others have appeared before them in connection with medical legislation. They always want to know -what we have done for the community. Of course, our one reply has been that we have done so much in preventive medicine. The average legislator does not understand or comprehend what you mean by preventive medicine.
He wants to know what you can do for the citizen when sickness comes upon him suddenly and when the citizen is unprepared financially to cope with sickness, and it is now time for us to present some definite constructive program that will not only suit the public, take good care of the sick, preserve the rights of the medical profession, and get rid of the objections and criticisms which are coming more frequently of late from half-baked philosophers with halfbaked ideas.

\section{How Can the Shortage of Nurses be Met?}

By Joseph B. Howland, M.D., Boston.

Florence Nightingale, the founder of modern nursing, was born 100 years ago, and this year, when the centennial of her birth is being celebrated, we hear from all parts of the country that fewer women than formerly are entering the profession she did so much for.

We also learn that in some states there is a shortage of nurses for private nursing. During the war it was to be expected that fewer graduate nurses would be available for any other than war service but we should probably not have. thought much about it if it had not been for the influenza epidemic. This past winter the same conditions prevailed for a short time. In Boston, at least, during the early winter and this spring, the registries have been able to supply the demand for nurses for private nursing. It is true that not to the same extent as formerly can the better educated and better trained nurses be obtained for private work, and this has caused much unfavorable comment by physicians.

We know that hospitals all over the country during the war took in many more than their normal number of pupils in an endeavor to meet the country's needs and it is fair to suppose that in doing so they drew on the supply of women who have entered later.

To just what extent this affects the present situation we can only guess, but it must be taken into account. That there are other important causes, all training school principals agree, and it is well known that the shortage of pupils was showing itself before the war.

Perhaps a brief review of the progress of nursing in this country may throw some light on the present situation. The first training school for nurses in the United States was established at the New England Hospital for Women and Children in Boston in 1872, and 
in the following year training schools wer opened in Bellevue Hospital, New York, at th New Haven Hospital, and at the Massachusett General Hospital. Although at the beginnin: the hospital authorities were not without mis givings as to the success of the new venture, $i$ did not take trustees, physicians, and the pub lic long to see that a new profession of inestima ble benefit had made its beginning in America The trained nurse gradually replaced the un trained attendant who usually had little educa tion, not much ambition to learn and who oc casionally approximated in many respects the celebrated Sairy Gamp.

As trained nursing became better known, large numbers of well-educated women, who desired $t_{0}$ be independent, entered training schools, as there are few other desirable fields in which they could earn their own living. Until nurse training became popular, unless they married or took up school teaching or music teaching, they continued to live at home. After completing a course of training a few became superintendents of training schools; the great majority, however, if they practised their profession must do institutional work or private nursing. The broad field in which nurses may work today had not been dreamed of. A most important step in the progress of nursing dates from 1893, at the time of the World's Fair in Chicago. At this time, at a meeting of the Hospital and Medical Congress, it was suggested that a sub-section of nursing be formed. This was done and Miss Isabel Hampton, Superintendent of Nurses of Johns Hopkins Hospital, was made chairman. As a result of this meeting a few days later a small group of training school superintendents, women who realized the incompleteness of their own training and who wished their pupils to benefit by their experience, met again and founded an association of training school superintendents which later became the National League of Nursing Education, an association which has done much for the advancement of nursing. Miss Sophia Palmer and Miss M. E. P. Davis, both graduates of the Massachusetts General Hospital Training School, were conspicuous members of this first gathering. Miss Palmer continued actively in educational work until her death this past winter.

About 20 years ago other opportunities than nursing began to attract educated women, such as library and secretarial work. During the past decade, social service, domestic science, edical gymnastics, and occupational therapy, ave been added to the list. More recently many ell-educated women may be found in commerce, olding important places in stores as teachers i salesmanship, window-dressers, decorators, nd as store-guides.

Not a great many years ago when a young oman wished to become a nurse she wrote to a ospital applying for admission to the training chool, and if accepted, saw for the first time $n$ the day of her admission, the hospital that vas to become her home for two or three years nd which was to give her training for her areer. It is not so today; candidates make ong journeys to look over the hospitals they re considering and before they decide ask many iearching questions in an endeavor to find out he strong and weak points of the rival schools hey are to choose from. A great many hospitals conducting training schools still have too lew paid instructors, too long hours, too much domestic work, unsuitable living quarters, and too little in amount of variety of elinical material to attract the kind of women we want to become nurses. Today we find some physicians advocating a return of the old standards of 20 years ago, as if such a backward step would again attract the same sort of women who then entered training. They do not seem to realize that conditions have changed. It is the school with the standards of 20 years ago that is crying loudest today for pupils, and as a rule only the more progressive schools have full classes. It must be admitted that not all schools are so fortunate, but in the main this is so. It is certain that the training school of the future will be less dependent on the hospital for its support.

Many hospitals have from their beginning had difficulty in raising money enough for their charitable work and their training schools have shared in this lack of funds. Some, in fact, have done so little that it is surprising that they have been able, year after year, to obtain students.

There is today a distinct tendency to separate more widely the theoretical work from the practical training in the hospital as evidenced by the so-called University Training Schools. Upon her return to England from the Crimean War, Florence Nightingale was given fifty thousand pounds by the grateful people of England. She accepted it only with the understanding that it was to be used to found a school of nursing which might train women along the 
lines she advocated. The Nightingale School of Nursing which she established in connection with St. Thomas' Hospital in London, was the first endowed training school for nurses, and after all these years since its beginning, I know of no other on such a completely independent educational basis.

An important conference took place in New York last February at the instance of the Rockefeller Foundation. There were present educators, hospital trustees, superintendents of hospitals and training schools from all over the United States and Canada to consider the present nurse training situation, and its future. We may look forward with interest to the report of the committee appointed to study the subject. It seems to me safe to predict that there will be plenty of nurses for the important work they have to do when the public are fully awake to the necessary steps to make training again as comparatively attractive as it was some years ago.

We, as physicians, would do well to second the efforts of training school superintendents in their endeavor to make hospital trustees and superintendents see that their training schools have really educational courses; that casual, poorly prepared lectures by members of the staff are not an equivalent of well planned courses by paid instructors; that the large amount of domestic work, so often expected of nurses, is not educational, deprives her of time needed to properly care for her patients and may well make her question the wisdom of the choice of her calling.

Managers of special hospitals, such as surgical, obstetrical, mental, eye and ear, and children's hospitals should appreciate the fact that they cannot properly maintain training schools without ample affiliations to give their pupils the necessary all round training.

The field of public health nursing is expanding so rapidly that it seems almost impossible to meet the demand from this quarter altho many of our best nurses are taking up the work. A public health nurse may be a school nurse, an industrial nurse, a district nurse, an infant welfare nurse, and in small communities she may be a combination of these. They all have certain things in common, namely, that their hours of work are regular and well defined and may permit a woman in her off duty hours to live at home in an entirely different atmosphere from that of her labors, a fact of no small importance. Then again as a rule the importance of her work is appreciated by those whom she serves; she is looked up to as a friend, adviser, and educator.

It is increasingly difficult to get desirable graduates to return to hospitals as head nurses, a fact to be deplored, for we need the best of them as practical instructors to the pupils in training. It is probable that the long hours and the inability to live independent home lives have much to do with it. These conditions can be remedied as there seems to me no reason why most head nurses could not live outside of the hospital. Those few who for good reason must be on call should be provided with ample well-furnished living rooms.

More and more, hospitals are caring for the wealthy as well as the poor and although the well-to-do find it more difficult in some localities to get hospital accommodations, there is a growing tendency to provide for their needs.

It does not seem to me likely that our better trained nurses will again be available to the same extent as formerly for private duty for chronic cases and minor illnesses, and who can iblame them? The necessary care for these cases can be given by trained attendants. Then, also, there is not the same helplessness in the home as formerly when sickness occurs, thanks to Red Cross Home Nursing courses. Hourly nursing will help to supplement the work mothers thus trained can do.

If attendants are to be trained to help with private nursing and work in special hospitals their status should be clearly defined. At present they not infrequently pass themselves off as trained nurses; if this is allowed to continue it will tend to discourage women from taking three-year training courses. This state of affairs should be remedied if compulsory registration laws were generally enacted establishing clearly the two kinds of service so that the public would know exactly what to ask for and what to expect when applying to registries for nurses and attendants.

The prospect of having enough nurses for our future needs does not seem to me discouraging. It merely means that we must adjust ourselves to changing conditions and not try to retard progress. Women are naturally attracted to nursing, but because there are so many other fields for them to choose from will not select this profession unless they have as 
good a prospect to live as happily in it as in other work.

It seems to me that we, as physicians, have a particular responsibility in the matter. We know the kind of women we need as nurses and we can do much to make this clear to the public generally.

If, as seems to me, we badly need large numbers of well educated women in the nursing field we can do much to help get them, not by criticizing those we have but by helping them to place our schools on a better educational basis. This we can do by showing the public, who are to be benefited by an adequate supply of nurses, that their part is to supply the necessary funds for the support of the training schools.

\section{DISCUSSION.}

Dr. F. A. WAshburn, Boston: I can add very little to Dr. Howland's excellent and very complete paper. Perhaps I can emphasize a few points, however. I would like to say first of all that the country is now prosperous. Times are good. Dr. H. B. Howard used to bring out this point to me a good many times,- that when we have bad times, they were good times to run a hospital. In other words, you had plenty of candidates for your training school. In times of prosperity there are so many other avenues of employment open to women and every class of people who work in hospitals that the supply is limited. This matter of good times will rectify itself. Some say soon and some later, but hard times are sure to come, and when they do come, I for one look for a very marked increase in the number of applicants for our training schools. The question really divides itself into two parts. The first part is the scarcity of applicants for our training schools, and the second is the scarcity of women who go into private practice. That is, the small proportion of our graduate nurses who go into private practice. It is an undoubted fact that some hospitals have exploited nurses. Some of the small hospitals and some of the large ones have not given a quid pro quo. In other words, they have not given a complete training. They have secured their nursing at reduced rates, and have not given the equivalent in training. The nurses are awake to that, and as Dr. Howland pointed out, they look up the qualifications of a school pretty carefully before making a choice. Those hospitals are just trying to get something for nothing, and they must change their methods. If they cannot change to better methods, hire more competent instructors, and make a real school by utilizing their own hospital and by affiliation, they cannot give the proper equivalent to a nurse and they will have to get their nursing in some other way. What will that other way be? I can see only one thing for them to do aside from closing their doors, and that is to hire enough graduate nurses and to have a school for attendants. I don't mean by that that they should do their nursing of acute cases by attendants, but that they should go to the expense of hiring enough graduate nurses so that the nursing is done by competent women, and so that they can train attendants. Then let us have a compulsory registration law, which we absolutely need in this state. Thus they can train and produce women who will be of great use in the community.

The other side of the question, the second part, is, what can we do to increase the pronortion of women who go into private nursing? As Dr. Howland pointed out, the opportunities for a trained nurse are very much greater today than they were a few years ago, infinitely greater than ten or fifteen years ago. The public health field has recently been opened, as you know. That has taken a large number of nurses from the private nursing field. The industrial nursing,-you know how many of our corporations have nurses on their payrolls, - the district nursing, and other lines of nursing are very much more attractive to an intelligent, educated woman because she is mistress of her own time, she can live in her own home, she has certain specified hours of work and she can live with her family. Now you must compete with that condition. It is here to stay, and how are you going to meet it? Taking care of the sick in the private home is the woman's natural function, and if the conditions are made as attractive as can be, trained nurses will consider them more favorably. In the first place, we can all do something to make a nurse's career attractive. How many of you men here would recommend your own daughters to be private nurses? If that question was asked you by your daughter would you back her up in doing it? If not, then let us put nursing where you will approve of it as a career for your daughter. Now that means the consideration of the nurse by the doctor. Usually she gets pretty good consideration from the doctor on the case. She does not always get it from the family, however, but the doctor can see to to it that she does get it from the family. Nine times out of ten what he says and the way he insists upon the woman being treated carries great weight and will settle the question. The private nurse will probably never in the future be in such large numibers that she can be at the beck and call of those with sufficient money to have her come on cases where her skill is not really needed. You do not need a trained nurse to care for a senile man or woman. An attendant can do that perfectly well. If you want some nursing supervision you can have your district nurse go in and supervise. You do not need a trained 